\title{
Integrity during pandemic times: The case for flexible adamancy
}

\author{
VIJAYAPRASAD GOPICHANDRAN
}

\begin{abstract}
The Covid-19 pandemic has dominated people's lives since late 2019, for more than nine months now. Healthcare resources and medicine have been completely consumed by the Covid 19 illness globally. This is a particularly difficult time for health systems because of the onerous responsibility to care for large numbers of sick people, protecting populations from contracting the infection by effective quarantine, isolation, and containment measures. In addition to this burden of work, healthcare providers are also overcome by fear of contracting the infection and transmitting it to their loved ones. It is during such difficult times that the integrity of healthcare providers is challenged. In this paper I will describe some challenges that a healthcare provider in a typical low resource setting faces during this pandemic time, and will propose the idea of "flexible adamancy" to address these challenges to the health system's integrity.
\end{abstract}

Keywords: integrity, medical ethics, pandemic, Covid-19

\section{Integrity in healthcare}

Integrity is defined as "holding on to one's beliefs and positions even when these are under attack and also holding this position consistently over time and situations"(1). For example, a community health worker who consistently performs her duty of making home visits to check on her pregnant patients, despite the temptation to skip the visits and work part time in a private hospital for extra earnings can be said to be a person of integrity. In other words, integrity stands for being single- mindedly focused on one's ethical values and obligations, not allowing oneself to be affected by any other external influences (2). An individual's integrity to their principles is challenged mainly in three situations: when there are more attractive alternative options available; when sticking to their principles involves possible danger to self or others; and when there is weak or no supervision to keep one on the straight and narrow path. In the example

Author: Vijayaprasad Gopichandran (vijay.gopichandran@gmail.com), Assistant Professor, Department of Community Medicine, ESIC Medical College and PGIMSR, KK Nagar, Chennai 600078 TN INDIA

To cite: Gopichandran V. Integrity during pandemic times: The case for flexible adamancy. Indian J Med Ethics. 2021 Jan-Mar; 6(1) NS: 10-12. DOI: 10.20529/IJME.2020.097

Published online first on September 17, 2020.

Manuscript editor: Sunita VS Bandewar

Peer Reviewers: Aamir Jafarey and Shrinidhi Datar

(c) Indian Journal of Medical Ethics 2020 above, the community health worker who does her duty, giving up the opportunity to make extra money, has the kind of integrity which resists temptation. When the same healthcare worker continues to carry out her duties even during times of danger and difficulty, she would be displaying the type of integrity in the second situation above. This kind of integrity becomes relevant in the context of the current Covid19 pandemic.

\section{Integrity during Covid 19: what are the challenges?}

The Covid-19 pandemic has completely overwhelmed health systems in most countries, worldwide (3). During the early days of the pandemic the health systems in Italy, Spain and New York were overwhelmed (4). What was a distant threat in March is now a reality in most low- and middle-income countries. Here I describe some of my observations while working as a healthcare provider during this pandemic and reflect on some measures to overcome challenges to one's integrity.

The greatest challenge to the integrity of healthcare providers in today's circumstances is the overwhelming fear of contracting the infection oneself as well as endangering one's near and dear ones. Healthcare providers are falling sick with the Covid-19 virus, and several have died (5). Many mid-level providers also have multiple comorbid illnesses like diabetes, hypertension, and coronary artery disease, perhaps partly due to their years of stressful work, and this puts them at a higher risk of developing serious complications of Covid-19. These mid-level workers are indispensable to the hospital and the healthcare eco-system, as their experience and expertise anchor the functioning of the entire system. But they are also vulnerable to the infection. Many others, especially nurses, interns, and resident doctors, are young women who are the primary care givers in their families, tending to both children and the elderly in their families. They are seriously conflicted between caring for their families and discharging their professional duties. This conflict is, in itself, a challenge to the integrity of the healthcare provider. Though they may be at low risk of serious infection, they could carry the infection home where they can give it to the elderly. There is almost no category of healthcare provider whose integrity is not seriously challenged by this overwhelming fear of infection.

To minimise the risk of infection to healthcare providers, health systems are following duty rotations planned so that each individual is allotted a certain number of shifts followed by a few days of quarantine. This effectively limits the number of active persons in the field or hospital on any given day. Further, some personnel in high risk contact with Covid-19 patients in non-Covid 19 areas of the hospital are also quarantined to prevent transmission to other patients. This puts additional pressure on the staff on duty, which is already limited. There are hospitals and Covid Care Centres where 
there is one doctor on duty to care for about 80-100 patients. Ms Parvathy (name changed) a 48 year old sales woman at a textile showroom in a metropolis, who was just discharged from a Covid care centre in a hospital said, "It was like a hotel stay. They provided us food three times a day. There was television running all the time. There were no doctors, nurses who even came near us. Nobody checked us, nobody gave us any specific treatments." This condition of under-staffed, overworked human resource systems is another major challenge to the healthcare staff 's integrity (6). For example, a resident may be so overwhelmed by her duty that she examines only the first 10 patients in the ward and for the rest she just copies down the clinical findings from the previous notes on the case sheet, thus missing out on any new important developments in the patients' health status.

The health system provides a range of supportive supervision, in the hospital or in the field, during healthcare delivery (7). Such supervision ensures accountability. A good level of supportive supervision encourages integrity in the healthcare provider to an extent. Though integrity is largely an internal trait of the individual, supportive supervision provides the much needed regulation, support, motivation and incentive to maintain integrity. However, the pandemic time has seen a reduction in the level of supportive supervision. Many of the supervisory staff are at higher risk of serious infection due to their age and the presence of co-morbidities which increase with age, and so are not able to provide hands-on support to primary health workers. In many settings, the supervisory staff monitor the functions of the primary level staff through close circuit televisions and mobile phone-based instructions. This lack of effective on-the-ground monitoring and supervision serves as a further challenge to the integrity of the healthcare provider.

The healthcare provider fears contracting the infection, is overworked and unmotivated and nobody is watching; this becomes the perfect recipe for lack of integrity in practice.

\section{Is compromised integrity an alternative?}

One of the dominant narratives in hospitals and public health offices is: "during such pandemic times, ethics is an obstacle". Leaders of healthcare institutions are hesitant to hold healthcare providers accountable or take strict action against those who violate professional standards, such as not reporting to duty or refusing to perform procedures on patients. "At least some work is happening now. If I start punishing them even this will stop and people will leave" they say to justify their position. In highly bureaucratic public health institutions, accountability has always been a challenge. The experiment of building community accountability mechanisms in the public health system has largely been a failure in the Indian context (8). The National Rural Health Mission had a built-in community accountability mechanism in which community members reviewed and monitored the functioning of the health system. This did not go down well with the health system as they were not used to being questioned and held accountable (8). Therefore, this mechanism failed to achieve its goal of establishing community accountability. The compromise in integrity pervades both Covid-19 and non-Covid-19 care. Patients lie in isolation wards and Covid care centres without even being examined once by a healthcare provider, and many of them deteriorate without being detected. The pandemic is used as an excuse to practise healthcare in a suboptimal fashion. But is such compromised integrity acceptable? What are its consequences?

If healthcare providers perform their duties improperly, it can lead to long term harm to patients and loss of life. A healthcare provider who is afraid to enter the Covid-19 isolation ward and so just conjures up a capillary blood glucose value for a diabetic patient taking insulin, without actually measuring it, may miss hypoglycaemic episodes which can even lead to coma. A community health worker who skips door to door surveillance of the last house in a street, may miss a symptomatic infected person in that house, thus losing the opportunity to contain the infection in that community. There are several reports of serious harm and loss of life due to lack of integrity in providing care for patients with Covid-19 (9). The death of an acutely breathless 44-year-old woman in a hospital in Gurgaon, due to alleged failure to provide oxygen for fear of Covid-19 created ripples in the media (10). The community depends on high levels of integrity in healthcare providers and the health system for its welfare. Professional integrity is the bedrock of trust in the health systems (11). Lack of integrity rapidly erodes trust. The health system and healthcare providers must live up to public expectations, especially during emergencies. It is also an ethical imperative for the health system to provide an enabling environment to practise such a high level of integrity.

\section{Maintaining integrity during difficult times -practising "flexible adamancy"}

Debates on how to practise ethical healthcare during pandemics and emergencies are often inconclusive. The idealist side of the debate stands for integrity, trust, moral values, and ethics while the pragmatic side argues that unless one is flexible one cannot get work done during emergencies. The confusion arises because being flexible is confused with making compromises. Flexibility is giving space for modifications in protocols, work timings, shifts etc. without leading to any adverse effect on outcomes; whereas compromise is accepting adverse outcomes to accommodate changes in working patterns, timings, etc. For example, it may be acceptable as an act of flexibility to give only morning and afternoon shifts to young nurses who are caregivers at home, to enable them to maintain a balance between work and personal life, but an unacceptable compromise for a middle aged nurse to stay out of the ward during duty timings for fear of getting infected. Yet another example of acceptable flexibility is for a diabetic patient to be seen by a general doctor due to the human resource crunch, but an unacceptable compromise to turn the patient away without any medication. Uncompromising flexibility is possible, and it needs to be effectively worked out by health systems.

A certain level of adamancy or adherence to core ethical values is always essential, pandemic or otherwise. Always keeping the people's best interest in mind, never doing any harm, treating all equally without any discrimination, and respecting each person's individuality, personhood and autonomy are some of these core ethical principles (12). Some important values in clinical medicine such as providing evidence-based competent care, considering the patients' social, financial, and familial contexts while planning care, collaborating with patients in decision making, respecting the patients' personhood, protecting their rights, ensuring equity by providing more care for those who need it more, and ensuring integrated and coordinated care cannot be 
compromised at any cost (13). While staying adamant about these core values, the health system must also practise flexibility to ensure pragmatic functioning of the system. The flexible adamancy paradigm is both at the healthcare provider level and the systemic level. It is the responsibility of health system leaders to rise to the occasion and demonstrate the highest form of integrity to core values and principles in all their decisions; because as the late US President Truman said, "The buck stops here". The health system must provide the right balance of pragmatic flexibility and adamancy in core values and this enabling environment will help healthcare providers uphold their personal integrity.

While it is important to discuss the integrity of the health system as a whole, it is essential to remember that the personal integrity of healthcare providers also largely contributes to the integrity of the system. It can be difficult for individual healthcare providers to maintain their integrity in a hostile health system environment. For example, when the hospital over burdens a few healthcare providers (usually the junior most and the most vulnerable) and lets others go free, it cannot expect these healthcare providers to work with the highest levels of integrity as burn out is likely to pose a major threat. In such hostile environments, working with integrity may itself be excessively burdensome. A system which does not provide an enabling environment to practise medicine with integrity may not be entitled to high levels of integrity from its health workforce. However, there are virtuous healthcare providers who retain their integrity despite adverse health system conditions and these providers must be role models for others.

There is a need for solution-oriented thinking to ensure this balance between adamancy in the core values and flexibility in handling the situation on the ground. I would like to conclude with a case example of how a health system managed to practise flexible adamancy during the Covid-19 period through solution-oriented thinking. A woman came to a health facility, 38 weeks pregnant, with a Covid-19 positive report. She was completely asymptomatic, and her Covid-19 test was done during a door to door screening in a containment zone. She was confused and anxious about this positive result and came to the health facility where her pregnancy had been registered, and all her antenatal monitoring done so far. She was not in labour; she was asymptomatic and otherwise healthy besides the Covid-19 positive status. The hospital only had a non-Covid-19 labour ward, so even if she went into labour she could not be delivered in that hospital. The standard protocol of the hospital was to refer such women to a bigger obstetric super specialty hospital which had a dedicated Covid-19 labour ward. However, the woman and her family were extremely distressed about going away so far to a strange health facility for the delivery. So, the healthcare provider advised home isolation for the woman for two weeks, following which they repeated the PCR test which was reported as negative. So, she could deliver normally at the same institution. This example does not involve any highly innovative solution to a serious problem. However, it is a typical example of flexible adamancy. The healthcare providers were adamant about providing patient-centred care, keeping the best interest of the woman in mind. They were flexible about their protocol in a non-compromising manner, and could practise healthcare with integrity.

\section{Conclusion}

The Covid-19 pandemic has thrown up several new and unusual challenges to the integrity of health systems and healthcare providers. Such testing times demand the highest levels of integrity to preserve the people's trust in health systems. Flexibility without compromising on care, while being adamant about the core values of beneficence, nonmaleficence, autonomy and justice is the best way to provide trustworthy healthcare during pandemic times.

\section{Conflict of interest: None declared.}

\section{References}

1. Nayak D, Sarukkai S. Integrity in medical practice. Indian J Med Ethics. 2014 Oct-Dec [cited 2020 Aug 9];11(4):203-5. Available from: https:// ijme.in/articles/integrity-in-medical-practice/

2. Campbell A. Can virtue prevail? Safeguarding integrity in medicine and science. Indian J Med Ethics. 2013 Jan-Mar[cited 2020 Aug 9]; 10(1): 11-13. Available from: https://ijme.in/articles/can-virtue-prevailsafeguarding-integrity-in-medicine-and-science/

3. Walker P, Whittaker C, Watson O, Baguelin M, Ainslie K, Bhatia S, et al. Report 12:The global impact of COVID-19 and strategies for mitigation and suppression. London UK:WHO, MRC Centre for Global Infectious Disease Analysis; 2020 Mar 26[cited 2020 Aug 9]. Available from: https:// www.imperial.ac.uk/mrc-global-infectious-diseaseanalysis/covid-19/ report-12-global-impact-covid-19/

4. Rosenbaum L.Facing Covid-19 in Italy-ethics,logistics, and therapeutics on the epidemic's front line. N Engl J Med. 2020 May 14;382(20):1873-5.

5. Adams JG, Walls RM. Supporting the health care workforce during the COVID-19 global epidemic. JAMA. 2020 Apr 21;323(15):1439-40. doi: 10.1001/jama.2020.3972.

6. Changoiwala P. Covid-19 Threatens to Overwhelm India's Health Care System. Undark.org. 2020 Apr 14[cited 2020 Aug 9]; Available from: https://undark.org/2020/04/14/covid-19-india/

7. Kok MC, Vallières F, Tulloch O, Kumar MB, Kea AZ, Karuga R, et al. Does supportive supervision enhance community health worker motivation? A mixed-methods study in four African countries. Health Policy Plan. 2018 Nov 1;33(9):988-98. doi: 10.1093/heapol/czy082.

8. Gaitonde R, San Sebastian M, Hurtig A-K. Dissonances and disconnects: the life and times of community-based accountability in the National Rural Health Mission in Tamil Nadu, India. BMC Health Serv Res. 2020 Feb 5;20(1):89. doi: 10.1186/s12913-020-4917-0.

9. Times Now. Shocking medical negligence in Bihar, lung patient kept in Covid-19 ward. Times Now. 2020 Jul 22; Accessed 2020 Aug 10. Available from: https://timesofindia.indiatimes.com/videos/city/patna/ shocking- medical-negligence-in-bihar-lung-patient-kept-in-covid-19ward/ videoshow/77099395.cms

10. Goel A. Gurgaon hospital booked for negligence after COVID-19 patient dies. Week.in. $2020 \mathrm{Jul}$ 24[cited 2020 Aug 9]. Available from: https:// www.theweek.in/news/india/2020/07/24/gurgaon-hospitalbooked-for-negligence-after-covid-19-patient-dies.html

11. Gilson L. Editorial: Building trust and value in health systems in lowand middle-income countries. Soc Sci Med. 2005 Oct;61(7):1381-4. doi: 10.1016/j.socscimed.2004.11.059.

12. Childress JF, Beauchamp TL. Principles of biomedical ethics. New York: Oxford University Press; 2001.

13. Dutch College of General Practitioners. Core values of General Practice/ Family Medicine. 2011[cited 2020 Aug 9]. Available from: https://www. nhg.org/sites/default/files/content/nhg_org/uploads/position_paper_ core_values_of_general_practice_family_medicine_sept_2011_0.pdf 